\title{
The Management System of Equipment Failure Service Based on HTML5 Standard
}

\author{
Xin $\mathrm{Yu}^{1}$, Peng Liu* ${ }^{*}$,Zheng-Da Jian ${ }^{1}$, Zhu-Wei Zhou ${ }^{2}$,Tian-Wei Ye ${ }^{1}$,Wei \\ Wang $^{1}$,Xiang Zhang ${ }^{1}$, Mei Le ${ }^{1}$ and Xin Chen $^{1}$ \\ ${ }^{1}$ The Institute of Mechanical Science and Engineering, Jilin University, Changchun, China \\ ${ }^{2}$ Shanghai GKN Drive Shaft-Changchun Co., Ltd. Chang chun, China \\ ${ }^{*}$ Corresponding author
}

\begin{abstract}
Keywords: Equipment Failure, HTML5 Standard,Equipment Maintenance
\end{abstract}
\begin{abstract}
Using information to realize manual equipment repair service can improve the efficiency of equipment maintenance, and master the latest information of operating status of equipment timely, and be propitious to statistics and archive information. Therefore, this paper proposes an equipment failuer repair service management system based on HTML5 Standard, what uses the international popular HTML5 standard to write. It can run on the mobile device and computer simultaneously and reflect equipment operational condition in real time, transmitting the information of equipment failure repair. The system's experiment in Fenterprise shows that this approach can shorten equipment maintenance cycle, and improve work efficiency, summarizing the short-term and long-term information on the equipment then managing equipment maintenance and worker performance.
\end{abstract}

\section{Introduction}

With the advance of industry 4.0, modern manufacturing technology requires the degree of enterprises intelligence and automation to become higher and higher, in order to meet the user's strict requirements for product diversity and timeliness. It also puts forward higher requirements for the production and operation capacity of the enterprise. The equipment in the enterprise must be ensured its continuity and high-speed. In the traditional equipment failure repair mode, when the equipment failure occurs, the production shift leader fill in repair orders, and repair orders are delivered to the factories' equipment maintenance department, then the equipment maintenance department sends maintenance workers for trouble shooting. The production shift leader check and accept after completion of equipment failure repairing. After acceptance, the maintenance records and acceptance records are filed and the managerscan count these data regularly or irregularly. When the equipment failure is not resolved, it is submitted to the engineering services, and then the engineering service contacts the equipment manufacturer to send maintenance specialists to repair. The traditional equipment repair has a longer cycle, which affects the production efficiency. In the highly developed mobile Internet technology today, ouring information management system based on HTML5 standards has became the mainstream of industrial applications. This technology can be developed directly on mobile devices, which guarantees the timeliness of information transmission. The new repair management system that use the technology transmits repair information in real-time and effectively, which is a reasonable way of shortening the repair cycle and improving work efficiency undoubtedly. Therefore, thispaper proposesan equipment failuer repair service management systembased on HTML5 Standard.The management system not only reflects the operation of each station equipment, but also can sendthe informationto all levels of management and the head of maintenance department through the mobile terminal APP in the event of equipment failure, timely. The system has been applied and popularized in Fenterprise (a joint venture of auto parts manufacturers). 


\section{The Management System of Equipment Failure Repair Service Based on HTML 5 Standard Design}

\section{Design Principles}

This system based on the HTML5 language of the jQuery and bootstrap technology, using the specification of HTML + CSS + JS as the standard of information interaction, using B/S framework design. B/S mode application system is composed of the browser and Server. The SQL Server database is installed on the server and making data interaction via the browser. At the same time, this system uses the advanced and mature software and hardware to support platform and uses related standards as the basis of the system. Rapid development/quickly modify system principle provides a flexible means of secondary development. On the component-oriented application framework, we are able to develop new business and add new features quickly without affecting system. At the same time we can provide convenience to modify their business and support dynamic loading. Ensuring application system could be able to support centralized version control and upgrade management conveniently.

\section{Process Design}

This paper mainly introduces a kind of equipment fault repair service management system based on HTML 5 standards, the specific process as shown in figure 1, concrete operation is as follows:

During equipment failure, the operators send the fault information to the group of mechanics and mechanics monitor distribute tasks to the mechanic. Timing starts at the same time, the system will send timeout information to the monitor, workshop section chief, workshop manager automatically, if more than 4 hours to overhaul the machine. After the completion, it will get a report for statistical data and the index of machine history failure data. It needs to send a report to the machine monitor, if the mechanic could not repair. The monitor will reallocate tasks and make job evaluation for the mechanic. If the equipment maintenance needs outsourcing, according to normal process operation, checking maintenance outsourcing in the maintenance report, the monitor is responsible for the outsourcing maintenance.

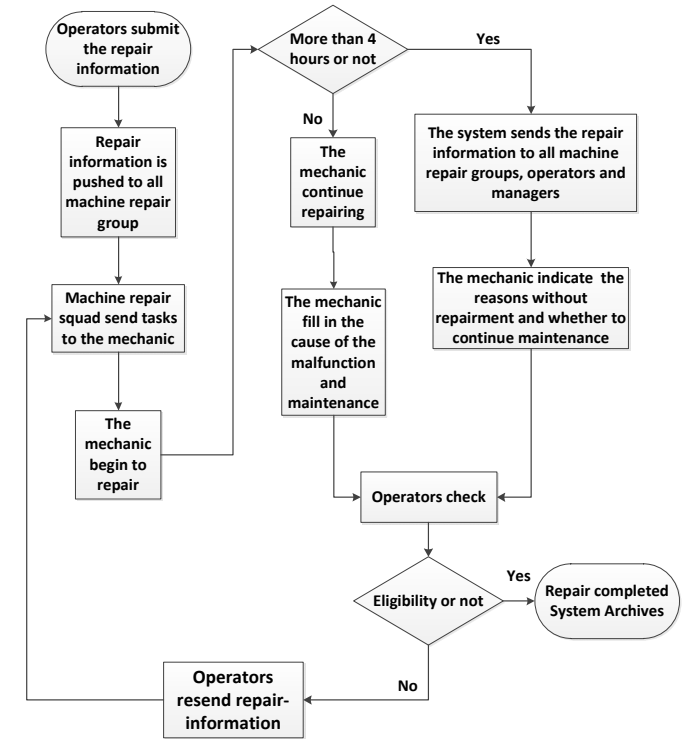

Fig.1Process Design

\section{System Functions}

\section{User Information and Rights Management Module}

This module includes four functions: login management, user management, equipment management, rights management. Its main function is to achieve users at all levels of the user login, 
manage user account usage, add or remove device information,receive allocation information and send permissions.

\section{Maintenance Tasks Reporting and Execution Module.}

After the equipment failure, the operation worker sends the breakdown information according to the different situation. The machine repair monitor assign tasks to operators. Whenthe repair task is completed, the section chief carries on the appraisal to this maintenance.Specific operation shown in Figure 2.

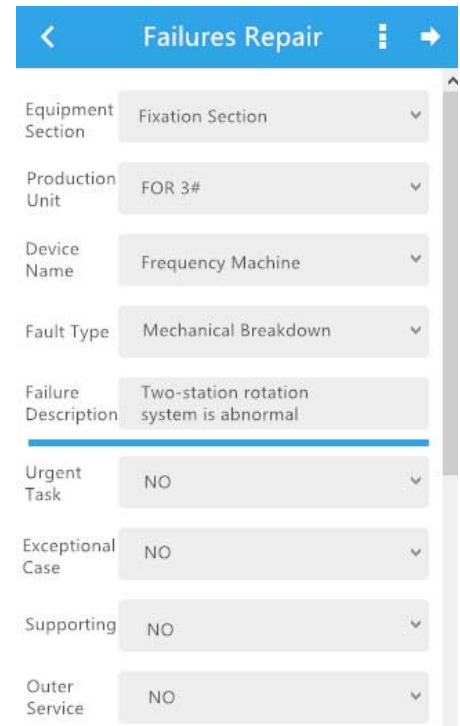

Fig.2 Maintenance mission reporting and implementation module

\section{Business Process Management Module}

The main function of this module is to monitor the progress of the maintenance tasks. The relevant personnel through the business process map real-time observe the progress of each maintenance task. When the process has been completed, the color will be lit up, and remaining the unfinished work white. Such as shown in Figure 3.

\section{flow-process diagram}

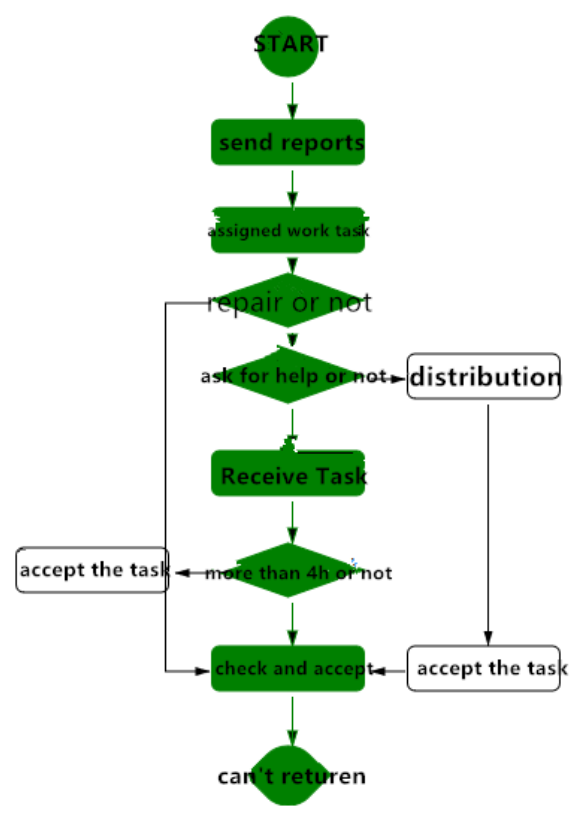

Fig. 3 Business process module 


\section{Production Equipment Status Monitoring Module}

This part of the main functions is completed in the PC-side. Based on the production data, the layout of the production lineis cycleing displayed in the terminal. When a machine failure can receive fault information, and then the fault of the production line where the machine is displayed to the screen, the fault machine marked red fault signal, as shown in Figure 4.Production monitor acceptance is complete, the fault mark disappears, the screen become normal machine condition.

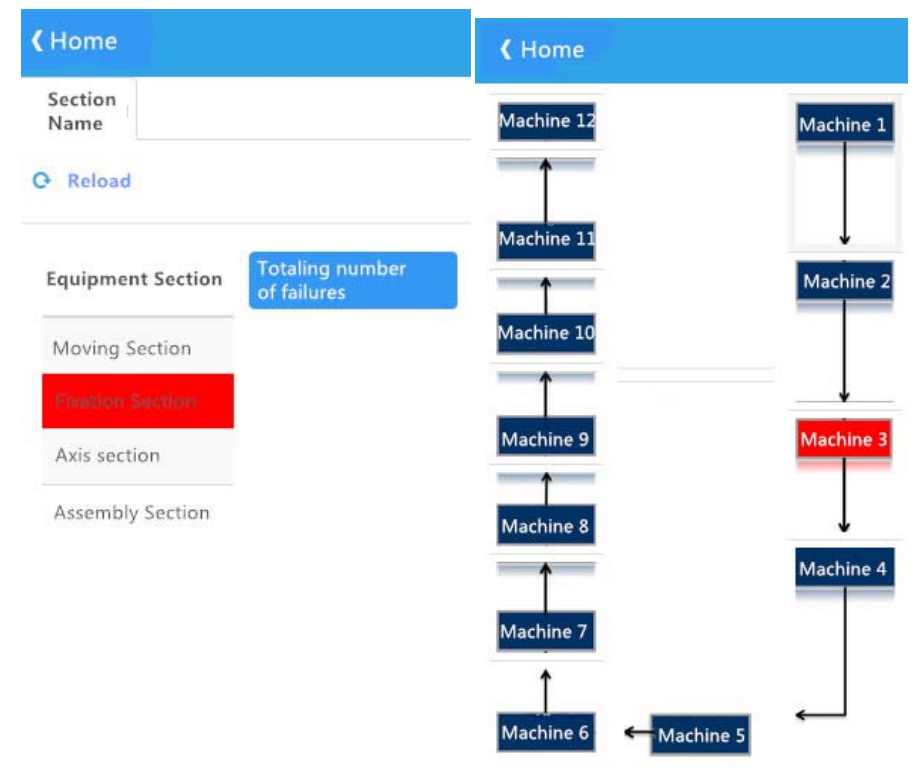

Fig. 4 Production equipment status monitoring

\section{Management Staff Statistics Module}

This module includes three main functions:

(1)Query the fault list. Administrators can use this module feature to view the current list of device faults.

(2)Query repair list statistics. Administrators can use this module function to view the current device repair list. When you click the query repair list button, by reading the repair list in the database, the return value to the form of the form output to the browser, the current equipment failure to understand. And the manager can count all maintenance records of a service person

(3)Query equipment maintenance records. Administrators can use this module function to view all current repair records for a particular device.

\section{Conclusion}

Based on the HTML 5 standard,this paper designs a kind of equipment fault repair service management system. The main function is completing real-time on-line fault repair service and handle and realizing the intelligent and informationalized the equipment management and improving the efficiency of equipment maintenance. Managers also can call maintenance data, which providing a reliable basis for performance appraisal and development plan. The system has been commissioned in F company nearly a year. To a certain extent, its strong practicability and good effect has solved some problems such asthe complex repair process, long repair cycle, difficult in statistical analysis, and so on. In this paper, the research results have important application value and can be spread in the discrete manufacturing enterprise.

\section{Acknowledgement}

This research was financially supported by JLU Training Plan of Innovation and Entrepreneurship. 


\section{References}

[1] Zhiqiang Jiang, Xilan Feng, Xianzhang Feng, Lingjun Li.A Study of SVDD-based Algorithm to the Fault Diagnosis of Mechanical Equipment System.[J]. Physics Procedia,Volume 33,2012:1068-1073

[2]V.V.Panteleev,V.A. Kamaev,A.V. Kizim.Developing a Model of Equipment Maintenance and Repair Process at Service Repair Company Using Agent-based Approach.[J].Procedia Technology, Volume 16, 2014:1072-1079

[3]A.V.Kizim,M.V.Denisov,S.V.Davydova,V.A.Kamaev.A.Conceptual Agent-based Model to Supporting the Production Equipment Technical Service and Repair Organization.[J].Procedia Technology,Volume 16, 2014:1176-1182

[4]NING Hui, SHI Yanbin, GAO Xianjun.Dynamic Simulation of the Equipment Repair Support System based on the OPN Model.[J].Procedia Engineering, Volume 23, 2011:284-289

[9]A.V. Kizim.Establishing the Maintenance and Repair Body of Knowledge: Comprehensive Approach to Ensuring Equipment Maintenance and Repair Organization Efficiency.[J].Procedia Technology, Volume 9, 2013:812-818

[5]Wang Yupu; Liu He; Liu Changkui; Lu Mingyan; Liu Mingzhen.The development of Drilling \& Production Equipment Management and Repairing Techinques in Daqing Oilfiled.[J].The Fourth World Conference of Maintenance,2008.11 